\title{
Drug Enforcement Administration
}

National Cancer Institute

\section{Source}

National Cancer Institute. Drug Enforcement Administration. NCI Thesaurus. Code C127110

The federal law enforcement agency, under the U.S. Department of Justice, tasked with enforcing the controlled substances laws and regulations of the United States. 